\title{
Body mass index and dental caries experience in Nepalese schoolchildren
}

Saujanya Karki ${ }^{1,2,3}$, Jari Päkkilä ${ }^{4}$, Tapio Ryhänen ${ }^{1}$, Marja-Liisa Laitala ${ }^{1}$, Manoj Humagain ${ }^{3}$, Marja Ojaniemi $^{2,5}$, and Vuokko Anttonen ${ }^{1,2}$

${ }^{1}$ Research Unit of Oral Health Sciences, University of Oulu, Finland, ${ }^{2}$ Medical Research Center Oulu, University of Oulu, Oulu University Hospital, Finland, ${ }^{3}$ School of Medical Sciences, Kathmandu University, Nepal, ${ }^{4}$ Department of Mathematical Sciences, University of Oulu, Finland, ${ }^{5}$ Department of Children and Adolescents, PEDEGO Research Center, University of Oulu, Finland.

\section{Author Contributions}

SK and VA made conception and designed the study. SK, MLL, MH and VA performed the acquisition of data. SK and JP performed the analysis and interpretation of data. SK, JP, TR, MLL and VA participated in preparing the manuscript. $\mathrm{MH}$ reviewed the manuscript and gave his comments. MO is a pediatric endocrinologist; she reviewed the manuscript and gave her critical comments.

\section{Corresponding Author}

Saujanya Karki

Research Unit of Oral Health Sciences

University of Oulu

POB 5281, Aapistie 3, FI- 90220, Oulu, Finland

saujanya.karki@,oulu.fi 


\begin{abstract}
Objectives: The aim was to investigate the severity of untreated dental caries among Nepalese schoolchildren and its association with their body mass index (BMI) using IOTF, WHO and Nepalese growth reference systems.
\end{abstract}

Methods: This school-based clinical cross-sectional study was conducted with three WHO index age groups (5-6-, 12-, and 15-year-olds) in 18 out of 75 districts of Nepal, selected using stratified random sampling. A total of 1,135 schoolchildren were included in the study. A validated structured questionnaire was used to assess the children's oral hygiene practices and dietary habits. Clinical oral examinations investigated the status of untreated dental caries in primary and permanent teeth $(d t / D T)$ along with its consequences ( $p u f a / P U F A$ ). Later, the grade of severity of untreated dental caries $(G U D C)$ was determined using both $d t / D T$ and pufa/PUFA. Height $(\mathrm{cm})$, weight $(\mathrm{kg})$, waist circumference $(\mathrm{cm})$, and hip circumference $(\mathrm{cm})$ were measured and the body mass index $(\mathrm{BMI})$, waist-to-hip ratio (WHR), and waist-to-height ratio (WHtR) were calculated. The findings were presented as proportions, and the Chi-square test was performed to compare differences between groups. Generalized linear mixed models with random effects assessed the association between the severity of untreated dental caries and the BMI.

Results: According to the IOTF, WHO, and Nepalese growth reference systems, the overall proportions of children with a low BMI were $38.6 \%, 15.4 \%$, and $12.8 \%$, and those with a high BMI were $7.9 \%, 4.6 \%$, and $8.4 \%$, respectively. Untreated dental caries was common among the youngest age group and those with infrequent tooth brushing habits or frequent consumption of sweet bakery products, sweets or candy, or tea with sugar. Neither a low nor a high BMI was associated either with $\mathrm{dt}+\mathrm{DT}$ or with pufa+PUFA, after adjusting for confounders. However, both a low and a high BMI (all three references) were associated with the severity of dental caries or GUDC.

Conclusion: Regardless of the growth reference system used, children with either low or high BMI may be at risk of developing untreated dental caries lesions and related consequences. Both underand over-weight/obese and dental caries share common risk factors, mostly dietary. Preventive and intervention approaches/strategies such as behavioral and dietary modifications should be implemented to improve both children's oral health and their nutrition in Nepal.

Keywords: Body mass index, children, dental caries, Nepal 


\section{Introduction}

According to a recent report, the global prevalence of untreated dental caries among 12-year-olds is $69.4 \%{ }^{1}$. Overall, the increase in the body mass index (BMI) among children and adolescents in highincome countries has plateaued ${ }^{2}$, whereas the incidence of dental caries has markedly declined ${ }^{3}$. However, malnutrition (both under- and over-nutrition) and dental caries remain major and emerging public health threats in low- and middle-income countries ${ }^{1,2}$. Also in Nepal, the prevalence of untreated dental caries among children and adolescents has increased from the past $\mathrm{t}^{4,5}$, and the proportion of overweight and obese adolescents and adult Nepalese women (15-49-year-olds) has increased from $9.0 \%$ in 2006 to $22.0 \%$ in $2016^{6}$.

The association between BMI and dental caries is still unclear ${ }^{7}$. Hooley et al. (2012) concluded in their systematic review that both high and low BMI are associated with children's dental caries ${ }^{7}$. Similarly, the association was also inconclusive in another systematic review, particularly concerning low- and middle-income countries as well as primary and permanent dentitions ${ }^{8}$. Both dental caries and obesity are multifactorial, and share common risk factors, such as dietary habits, life style, and socioeconomic conditions ${ }^{9}$. The availability and consumption of processed food products or drinks (containing a high amount of sugar, salt, or trans-fats), as well as sedentary lifestyle are considered major causative factors of overweight and obesity ${ }^{10}$. Likewise, frequent consumption of refined sugars and processed foods/drinks containing free sugars is considered a risk factor of dental caries ${ }^{11}$. In addition, poor oral hygiene habits have recently been reported to be associated with childhood and adolescent obesity ${ }^{12,13}$ again, risk factors for poor oral health, particularly dental caries. For children with low BMI, lack of nutrients is a risk factor for common chronic diseases such as dental caries, and also may cause developmental dental disorders ${ }^{14}$. On the other hand, dental pain and infections due to dental caries may have an impact on eating and sleeping, thereby resulting in a low weight and growth impairment ${ }^{15}$.

Body composition is influenced by environmental and nutritional, but also genetic factors. Therefore, children of different ethnicity may be misclassified as underweight/overweight/obese, if only one international growth reference system is used. Therefore, a recent study has recommended the use of nationality- or ethnicity-specific growth references ${ }^{16}$. There are three widely used growth reference systems, namely the World Health Organization (WHO), International Obesity Taskforce (IOTF), and Center for Disease Control and Prevention (CDC) reference systems. In addition, age- and gender-specified, population-specific BMI cut-off values were recently established for Nepalese 
children and adolescents ${ }^{17}$. A systematic review (papers published between 1980 and 2010) revealed that six studies used the CDC growth charts, three studies used the IOTF growth centiles, two studies used the WHO growth reference system, and the rest three papers used the population-specific growth charts to define the growth status of children and adolescents ${ }^{18}$. However, using only one reference system without considering the ethnicity may lead to the misidentification of possible risk groups for dental caries.

The present study investigated the severity of untreated dental caries among Nepalese schoolchildren and its association with their BMI using three different growth reference systems, i.e. the IOTF ${ }^{19}$, $\mathrm{WHO}^{20}$ and Nepalese ${ }^{17}$ systems. The hypothesis was that both a low and a high BMI are associated with untreated dental caries and its severity. We also investigated differences between the reference systems in their ability to detect associations between BMI and untreated dental caries.

\section{Materials and Methods}

This school-based clinical cross-sectional study was conducted among three WHO index age groups (5-6-year-olds, 12-year-olds, and 15-year-olds) in 18 out of 75 districts of Nepal during April-July 2016. The study protocol was approved by the Institutional Ethical Committee, Kathmandu University in Nepal (IRC No. 60/15, KUSMS), as well as by the Northern Ostrobothnia Hospital District in Finland (18/2016). The study was conducted according to the principles of the World Medical Association Declaration of Helsinki. Furthermore, a written permission to conduct the study was obtained from both the Ministry of Health and the Ministry of Education, Government of Nepal. The district health and education authorities also gave their permission for the study.

\section{Study sites and samples}

The methodology on the selection of the study sites and samples has been described in detail in a

previous study ${ }^{5}$. Briefly, the districts were selected following the stratified random sampling method, considering the ecological regions (Tarai, Hill, and Mountain) and the administrative developmental regions (Eastern, Central, Western, Mid-Western, and Far-Western) of Nepal. Three districts from each five developmental regions were selected and they also represented each ecological region. Altogether 27 schools (one to two schools per district) were selected. The sample size was calculated using the G*power software (GPOWER version 3.1, Samsovej 21, 8382 Hinnerup, Denmark) with power calculation of $95 \%$ and the Mann-Whitney $U$ test to analyze the difference between means (difference in the number of decayed primary and permanent teeth, $\mathrm{d} / \mathrm{D}=0.3$ ) with alpha-type error 
at 0.05 . After a power calculation, the sample size of $n=340$ in each age group was considered sufficient. The study participation / response rate was $99 \%(1,137 / 1,151)$.

Prior to the study, the schools were contacted via an informative letter describing the purpose and procedure of the study. A written consent was obtained both from the school headmasters and from the parents of the youngest children (5-6-year-olds). A verbal consent was obtained and recorded from the children belonging to the oldest age groups (12- and 15-year-olds).

\section{Oral health-related behaviors}

A structured questionnaire was used to gather information on the children's oral hygiene practices and dietary habits. This structured questionnaire on oral health-related behavior was previously piloted and validated in $\mathrm{Nepal}^{21}$. Face-to-face interviews were conducted with the parents of the 56-year-olds, and the 12- and 15-year-old children were asked to answer a self-administered questionnaire.

\section{Dental status}

The dental examinations were performed in classrooms using external (LED) headlights, intra-oral mirrors, and the WHO Community Periodontal probes following the WHO guidelines and criteria ${ }^{22}$. The participants were asked to lie down on a bench in the supine position, and the examiners were seated behind them. Cross-infection control was maintained in all examination phases, as per the protocol.

The oral findings concerning the status of untreated dental caries (decay in primary and permanent dentition, $d t / D T$ ) and infections due to untreated dental caries (visible pulp or pulp involvement, ulceration of the oral mucosa due to root fragments, a fistula, or an abscess, pufa/PUFA) were recorded according to the standard criteria ${ }^{22,23}$. The dental status was evaluated at tooth level based on a visual-tactile examination, without using fiber-optic trans-illumination (FOTI) or radiography or without cleaning the teeth professionally or air-drying the teeth. The examination protocol and the quality control and quality assurance processes have been described in detail in a previous study ${ }^{5}$. In short, a survey team composed of three trained and calibrated Nepali dentists conducted the clinical examinations. The findings were recorded manually on data collection sheets by two trained dental hygienists, who acted as enumerators. The training of the dentists, which took place in April 2016, covered theoretical sessions followed by practical sessions. The trainers were senior researchers 
familiar with similar studies. The inter-examiner kappa value for $\mathrm{d} / \mathrm{D}$ was 0.87 and for pufa/PUFA 0.63 , and the intra-examiner agreement ranged from 0.84 to 0.97 .

\section{Grading the severity of untreated dental caries (GUDC)}

To achieve a broader understanding of the prevalence of untreated dental caries $(d t / D T)$ and infection due to untreated dental caries ( $p u f a / P U F A$ ) based on clinical criteria, a new index, the grade of severity of untreated dental caries (GUDC), was created. The GUDC index consists of four grades determined based on the severity of both untreated dental caries $(d t / D T)$ and its consequences (pufa/PUFA) (Table 1). The number of untreated dental caries lesions, including both primary (dt) and permanent teeth (DT) lesions, and the respective sum score of teeth with caries lesions per person were calculated. The sum score per person for pufa/PUFA was also calculated in the same manner as above. Later, the sum scores of $d t+D T$ were classified into the following three categories: healthy (0), moderate (1-4), and severe (more than 4). The sum scores of pufa+PUFA were also classified into three categories based on the median and the proportion of teeth with infection due to untreated dental caries. The categories were: No infection (0\%), moderate infection (10\% or less), and severe infection (more than 10\%). The categorizations were done according to the distribution of $\mathrm{dt}+\mathrm{DT}$ and pufa+PUFA. The proportion of the sum score of $p u f a+P U F A$ was calculated separately for primary, mixed, and permanent dentition. Finally, the GUDC was computed and classified into four grades: Grade 1, Grade 2, Grade 3, and Grade 4 (Table 1).

\section{Anthropometric measurements}

Height and weight were measured by asking the children to stand upright with the back of the head, buttocks, and heels touching the stadiometer (without leaning backward or forward) and only wearing a light school uniform (shirt, trousers/skirt, and undergarments) and no head gear (cap, ribbon, hairpins, etc.) or shoes. The height $(\mathrm{cm})$ and weight $(\mathrm{kg})$ of the children were measured using a portable stadiometer (Seca ${ }^{\circledR}$, seca $\mathrm{GmbH} \&$ Co. KG., Hamburg, Germany) and a self-zeroing portable electronic digital scale (Rossmax ${ }^{\circledR}$, Rossmax Swiss GmbH, Berneck, Switzerland), respectively. The waist and hip circumferences $(\mathrm{cm})$ were measured after asking the children to stand with their arms wide open and feet positioned close together. The waist circumference (WaC) was measured at the midway between lower ribs and the iliac crest, and the hip circumference was measured around the widest portion of the buttocks. The measurements were done using an inelastic plastic measuring tape (Prym ${ }^{\circledR}$, William Prym Holding GmbH, Stolberg, Germany) held snugly (without compressing the skin) at a level parallel to the floor. 
The body mass index (BMI) was calculated using the formula: weight divided by the square of height $\left(\mathrm{kg} / \mathrm{m}^{2}\right)$. The waist-to-hip ratio (WHR) was calculated by dividing the waist circumference by the hip circumference, and the waist-to-height ratio (WHtR) by dividing the waist circumference by the height. During the training sessions, the members of the survey team were also trained to measure and record the anthropometric indices.

\section{Statistical analysis}

The manually recorded data were transferred into an electronic database to conduct analyses using the SPSS software (IBM SPSS Statistic for Windows, version 24.0. Armonk, NY: IBM Corp.). The kappa coefficient was used to measure the agreement between the untreated dental caries level (healthy, moderate, or severe), infection due to untreated dental caries (pufa/PUFA=0 and pufa/PUFA $\geq 1$ ), and the GUDC. Likewise, Spearman's correlation coefficient ( $\rho$ ) was used to assess the reliability between the indices.

The children were categorized according to their BMI to thin, normal, overweight, and obese using the three growth reference systems (i.e. $\mathrm{IOTF}^{19}, \mathrm{WHO}^{20}$, and Nepalese ${ }^{17}$ ). The participants were also dichotomized to normal and obese based on the cut-off values for central obesity (waist circumference, waist-to-hip ratio, waist-to-height ratio) of Nepalese children ${ }^{17}$. The distribution of thin, overweight, and obese children (using the three growth reference systems) was stratified by age and gender. Similarly, the distribution of dt+DT, pufa+PUFA, and GUDC in the participants was stratified by age (5-6-, 12- and 15-year-olds), gender (boys/girls), province, location (urban/rural), school type (public/private), tooth brushing frequency (twice or more daily /once daily / several times per week), dietary habits (consumption of sweet bakery products / consumption of sweets or candy / consumption of tea with sugar), as well as by the BMI (IOTF, WHO, Nepalese) and central obesity level (WaC, WHR, WHtR). The Chi-square test was applied to compare the differences between the groups.

For further analyses, the participants were categorized according to their BMI (all three reference systems) into children with a low (thinness/underweight), normal, or high (overweight and obese) BMI. Generalized linear mixed model with negative binomial distribution using random effect for sampling unit (schools) was conducted separately for each growth reference system, considering untreated dental caries (dt+DT), and its consequences (pufa+PUFA) as dependent variables. Sociodemographic characteristics (age, gender, location, and school type), frequency of tooth brushing, dietary habits, and the BMI were considered as covariates. The estimate of relative 
risk / Rate Ratio (RR) and 95\% confidence interval (95\% CI) were estimated for both crude and adjusted models. Similarly, a mixed effects multinomial logistic regression analysis was performed to analyze the association between the GUDC as a dependent variable and the BMI as a covariate. In the model, sociodemographic characteristics (age, gender, location, school type), frequency of tooth brushing, and dietary habits were adjusted. For the Odds Ratio (OR) and 95\% confidence interval $(95 \% \mathrm{CI})$ were also calculated. The level of significance was set at $p \leq 0.05$ for all the statistical tests. The statistical analyses were carried out using the SPSS software and R version 3.4.3 (R Development Core Team, Vienna, Austria).

\section{Results}

Out of the total 1,137 participants who completed both the clinical examination and the survey, only two children were excluded due to missing anthropometric measurement values. The prevalence of thinness/underweight, overweight, and obesity in the study samples according to the three growth reference systems, stratified by age and gender, are presented in Table 2 . The proportions of children with a low BMI (underweight or thinness) were $38.6 \%, 15.4 \%$, and $12.8 \%$ according to the IOTF, WHO, and Nepalese reference systems, respectively. Similarly, the proportions of children with a high BMI (overweight and obese combined) were $7.9 \%, 4.6 \%$, and $8.4 \%$ according to the IOTF, WHO, and Nepalese systems, respectively.

The agreement between the untreated dental caries $(\mathrm{dt}+\mathrm{DT})$ level and the new index used here for grading the severity of untreated dental caries lesions (i.e. GUDC) was substantial ( $\kappa=0.64$; $p$-value $<0.001)$. Additionally, a fair agreement $(\kappa=0.40 ; p$-value $<0.001)$ was found between the level of infections due to untreated dental caries (pufa+PUFA) and the GUDC. Furthermore, the GUDC had strong reliability with both $\mathrm{dt}+\mathrm{DT}(\rho=0.861 ; p$-value $<0.001)$ and pufa+PUFA $(\rho=0.817$; $p$-value $<0.001)$.

The associations of sociodemographic factors with dental caries and its consequences are presented in Table 3. In this study, two in three children had dt+DT $>0$, whereas one-fourth of the children had at least one tooth with pufa+PUFA (Table 3). In terms of the GUDC, almost half of the Nepalese schoolchildren achieved Grade 2 (only caries lesions) while a fifth were categorized into Grade 3 (caries lesions and pufa $>0$ in less than $10 \%$ of teeth). The youngest participants had significantly higher scores than the other age groups (dt+DT level, pufa+PUFA level, and the GUDC). The same was true for those brushing teeth only several times a week instead of on a daily basis, as well as for those consuming sweet bakery products, sweets or candies, or tea with sugar once or more daily. 
Obese (IOTF, Nepalese) or overweight (WHO) children had high dt+DT, whereas pufa+PUFA scores were high for thin children (all reference systems). In addition, the GUDC grade 4 was the highest for thin (IOTF, Nepalese) or underweight (WHO) participants (Table 3).

After adjusting for confounders, the estimated relative risk was higher among younger children (56-year-olds), and those who consumed sweets or candies, or tea with sugar once or more daily compared with the rest. Neither a low nor a high BMI was associated with untreated dental caries $(\mathrm{dt}+\mathrm{DT})$ and its clinical consequences (pufa+PUFA), in adjusted models (Table 4).

According to the mixed effects multinomial logistic regression analysis (Fig. $1 \mathrm{~A}, \mathrm{~B}$, and C), the association between high BMI (all reference systems) and the GUDC grade 3 was statistically significant (IOTF, OR 2.47, 95\% CI 1.27-4.78; WHO, OR 4.27, 95\% CI 1.75-10.56; Nepalese, OR 2.25, 95\% CI 1.19-4.23). Similarly, low BMI (IOTF) was associated with the GUDC grade 4 (OR $2.15,95 \%$ CI $1.17-3.93)$.

\section{Discussion}

This population-based cross-sectional survey revealed that untreated dental caries lesions co-exists with both low and high BMI values. The most severe or grade 4 of the GUDC (grading the severity of untreated dental caries) was associated with low BMI, whereas the grade 3 of the GUDC was associated with high BMI. However, untreated dental caries (dt+DT) and its clinical consequences (pufa+PUFA) alone were not associated with either of the BMI categories. This indicates that the nature of the association remains unclear. Furthermore, none of the reference systems was superior to the others in its ability to detect an association between BMI and untreated dental caries.

The high response rate (99\%) in a population-based study with randomized sample sites, and the inclusion of children from all the ecological regions and ethnic groups of Nepal are the strengths of this study. Because the diseases (untreated dental caries and its consequences) were common in the study sample, and the distribution was over-dispersed (variance larger than the mean), we performed a generalized linear mixed model with negative binomial distribution. Furthermore, the models were adjusted for possible confounding factors, such as sociodemographic characteristics (age, gender, location, and school type), frequency of tooth brushing, and dietary habits (sugar containing foods). Despite this, the results showed a positive concurrent association between untreated dental caries and a low or high BMI. The GUDC index used in this study estimates the burden of both untreated dental caries lesions (dt/DT) and its consequences (pufa/PUFA) in a single tooth-wise entity. The GUDC 
index simultaneously describes the severity of dental caries and the need for restorative work. In addition, in population-based epidemiological studies conducted in developing countries where radiographic assessment is not feasible, or might create a financial burden, the grading system used in this study could be practical. Furthermore, the index is simple (can be obtained with single clinical examination), brief (four grades and less time consuming), reliable (strong Spearman correlation coefficient), and reproducible (fair to moderate Cohen's kappa value). However, a detailed validation with some modifications to address shortcomings should be performed in the future. The crosssectional nature of this study is one limitation. However, the estimate of the relative risk and a narrow confidence interval computed enhance the strength of the association in a cross-sectional study, which was true here as well. Another limitation is that both overweight and obese children were analyzed as one category, i.e. children with a high BMI. The proportion of obese children in each gender and age group was below 5\% in this study, which is the reason to merge obese children with overweight children. It seems that being overweight/obese is still less common in Nepal than elsewhere although there are signs of an increasing trend of overweight among South Asian children and adolescents ${ }^{2}$. Furthermore, only one child had a high BMI (WHO) with the GUDC grade 4, leading to a wider confidence interval in Fig. 1.

An association between a high BMI and dental caries was established here; such a finding is contradictory to a recent study conducted in India, which showed an inverse association. In that study, a national growth reference system was used to classify BMI values ${ }^{24}$. Similarly, Liang et al. (2016) categorized BMI values according the WHO, IOTF, and CDC criteria and found an inverse relation ${ }^{25}$. The use of height-, weight-, and BMI-for-age z-scores among Bangladeshi children also showed negative association ${ }^{26}$. Our results are contradictory to those from Bangladesh, even though, the prevalence of pufa+PUFA $>0$ among our youngest schoolchildren was similar to Bangladeshi children $^{26}$. The possible pathway of association between the BMI and dental caries remains unclear in this study, regardless of the regression model used. A similar finding was also observed in a systematic review by Hooley et al. (2012) ${ }^{7}$. The association also remained unclear in a hospital-based study conducted among Moroccan adults ${ }^{27}$. However, this nonlinear "U-shaped" relationship between risk factors and disease outcome is not rare in epidemiological studies ${ }^{28}$.

The proportion of children with a low BMI was higher than the proportion of those with a high BMI, regardless of the reference system used in the present study sample. The relationship between untreated dental caries and low growth (BMI) and overall poor development may be explained by two mechanisms. The first one focuses on the overall poor child development caused by odontogenic 
infections $^{29}$, while the second one emphasizes the impacts (direct impacts due to functional limitation and indirect impacts due to body response) of untreated dental caries on the growth of children ${ }^{15}$. Children could avoid eating because of the pain caused by dental caries or pulpitis or abscess, leading to low body weight. For instance, significant improvement on body weight was observed among Filipino children after the treatment of infected or carious teeth ${ }^{30}$. A high decay score was also associated with nutritional deficiency and low weight in South Korean children ${ }^{31}$. Nevertheless, the impact of functional limitation due to untreated dental caries and its consequences on the growth and development of children should be studied in future. In contrast, common risk factors between untreated dental caries and obesity are easier to link to each other, as explained earlier. Furthermore, children with decreased masticatory function due to pain caused by dental caries also tend to swallow large food particles, thereby compromising a nutritional diet, shifting towards processed foods that eventually can lead to overweight/obesity ${ }^{32}$. However, longitudinal epidemiological studies are naturally the best approach to identifying temporal relationships.

This study showed that two-thirds of Nepalese schoolchildren have untreated dental carious lesions with varied severity, with the poorest situation in the youngest age group (5-6-year-olds). Furthermore, the same is also true for infrequent tooth brushing and frequent consumption of sweet bakery products, sweets or candy, or tea with sugar. The majority of the participants $(67 \%)$ in this study reported brushing their teeth only once daily; this could be one of the factors behind the high prevalence of untreated dental caries. Kumar et al. (2016) have reported an increased risk of carious lesions among those with infrequent tooth brushing habits ${ }^{33}$. Additionally, Nepalese children are exposed to sugar and sugar-containing foods at an early age (6-23-month-old), as reported in a recent survey conducted among mothers living in Kathmandu Valley ${ }^{34}$. It is necessary to modify the dietary habits among Nepalese children to have the intake of free sugars reduced to less than $10 \%$ of their total energy, as recommended by the $\mathrm{WHO}^{35}$. This would also benefit appropriate weight management as, although still low, the prevalence of overweight and obesity in Nepal is increasing ${ }^{6}$. Furthermore, considering the prevalence and distribution of sickness, the lack of oral health promotion and preventive programs as well as inadequate oral healthcare services should be taken into consideration while planning health and oral health policies.

In conclusion, irrespective of the reference system used, the majority of Nepalese schoolchildren have a normal BMI but the burden of low BMI is high. Both low and high BMI values (all the three reference systems) seem to be associated with an increased severity of untreated dental carious lesions. None of the reference systems was superior to another in their ability to detect an association 
between the BMI and untreated dental caries. This study also supports the well-established association between dental caries ( $\mathrm{dt}+\mathrm{DT}$ level, pufa+PUFA $>0$, and high $\mathrm{d} / \mathrm{D}+$ pufa/PUFA, combined or GUDC) and various influencing factors (e.g. sociodemographic factors, oral hygiene behaviors, and dietary habits). Both malnutrition and dental caries are preventable through a common approach. Policy-makers should integrate preventive and intervention strategies to improve both oral and general health in Nepal. 


\section{References}

1. Frencken JE, Sharma P, Stenhouse L, Green D, Laverty D, Dietrich T. Global epidemiology of dental caries and severe periodontitis - a comprehensive review. J Clin Periodontol. 2017;44 (suppl 18):S105.

2. Abarca-Gómez L, Abdeen ZA, Hamid ZA, et al. Worldwide trends in body-mass index, underweight, overweight, and obesity from 1975 to 2016: a pooled analysis of 2416 population-based measurement studies in 128.9 million children, adolescents, and adults. The Lancet. 2017;390:26272642.

3. Lagerweij MD, van Loveren C. Declining caries trends: are we satisfied? Current Oral Health Reports. 2015;2:212-217.

4. Yee R, Mishra P. Nepal national oral health "pathfinder" survey 2004. Oral Health Focal Point, Ministry of Health, HMG Nepal. 2004.

5. Karki S, Laitala M, Humagain M, Seppänen M, Päkkila J, Anttonen V. Oral health status associated with sociodemographic factors of Nepalese schoolchildren: a population-based study. Int Dent J. 2018;68:348-358.

6. Ministry of Health, New E, ICF. Nepal demographic and health survey 2016. Ministry of Health. 2017.

7. Hooley M, Skouteris H, Boganin C, Satur J, Kilpatrick N. Body mass index and dental caries in children and adolescents: a systematic review of literature published 2004 to 2011. Systematic reviews. 2012;1:57.

8. Chen D, Zhi Q, Zhou Y, Tao Y, Wu L, Lin H. Association between dental caries and BMI in children: a systematic review and meta-analysis. Caries Res. 2018;52:230-245.

9. Chi DL, Luu M, Chu F. A scoping review of epidemiologic risk factors for pediatric obesity: Implications for future childhood obesity and dental caries prevention research. J Public Health Dent. 2017;77 (suppl 1):S31.

10. World Health Organization. Report of the commission on ending childhood obesity. Geneva, Switzerland: $W H O ; 2016$.

11. Sheiham A, James WPT. Diet and dental caries: the pivotal role of free sugars reemphasized. $J$ Dent Res. 2015;94:1341-1347.

12. Virtanen JI, Muikku T, Similä T, Cinar AB, Pohjola V. Physical activity, BMI and oral health behavior among adolescents: Finnish school health promotion study. [published ahead of print Sep 24, 2018]. Eur J Public Health. doi: 10.1093/eurpub/cky193.

13. Li L, Wong HM, Gandhi A, McGrath CP. Caries-related risk factors of obesity among 18 -yearold adolescents in Hong Kong: a cross-sectional study nested in a cohort study. BMC Oral Health. 2018;18:188. 
14. Reyes-Perez E, Borrell LN, Katz RV, Gebrian BJ, Prophete S, Psoter WJ. Effect of early childhood protein-energy malnutrition on permanent dentition dental caries. Journal of Public Health Dentistry. 2014;74:181-187.

15. Alkarimi HA, Watt RG, Pikhart H, Sheiham A, Tsakos G. Dental caries and growth in schoolage children. Pediatrics. 2014;133:e623.

16. Bonthuis M, van Stralen KJ, Verrina E, et al. Use of national and international growth charts for studying height in European children: development of up-to-date European height-for-age charts. PLoS ONE. 2012;7:e42506.

17. Karki S, Päkkila J, Laitala M, Ojaniemi M, Anttonen V. National reference centiles of anthropometric indices and BMI cut-off values in a child population in Nepal. Ann Hum Biol. 2018. 45:447-452.

18. Hayden C, Bowler JO, Chambers S, et al. Obesity and dental caries in children: a systematic review and meta-analysis. Community Dent Oral Epidemiol. 2013;41:289-308.

19. Cole TJ, Lobstein T. Extended international (IOTF) body mass index cut-offs for thinness, overweight and obesity. Pediatr Obes. 2012;7:284-294.

20. World Health Organization. 2007 Growth reference data for 5-19 years. http://www.who.int/growthref/en/ [accessed April 4, 2018].

21. Karki S, Laitala M, Humagain M, Päkkilä J, Anttonen V. Adaptation and validation of a Nepali version of the Child-Oral Impacts on Daily Performances Index (C-OIDP). Community Dent Health. 2018;35:119-126.

22. World Health Organization. Oral health surveys: basic methods. 5th ed. Geneva, Switzerland: WHO; 2013.

23. Monse B, Heinrich-Weltzien R, Benzian H, Holmgren C, van Palenstein Helderman W. PUFA-an index of clinical consequences of untreated dental caries. Community Dent Oral Epidemiol. 2010;38:77-82.

24. Kumar S, Kroon J, Lalloo R, Kulkarni S, Johnson NW. Relationship between body mass index and dental caries in children, and the influence of socio-economic status. Int Dent J. 2017;67:91-97.

25. Liang J, Zhang Z, Chen Y, et al. Dental caries is negatively correlated with body mass index among 7-9 years old children in Guangzhou, China. BMC Public Health. 2016;16:638.

26. Mishu MP, Tsakos G, Heilmann A, Watt RG. Dental caries and anthropometric measures in a sample of 5- to 9-year-old children in Dhaka, Bangladesh. Community Dent Oral Epidemiol. 2018;46:449-456

27. Chala S, El Aidouni M, Abouqal R, Abdallaoui F. U-shaped association between untreated caries and body mass index in adults at Rabat dental University hospital, Morocco: cross sectional study. BMC research notes. 2017; 10:5. 
28. Lemmens P. U-Shaped Curve. In: Salkina NJ, eds. Encyclopedia of research design. Thousand Oaks, California: SAGE Publications; 2010:1587-1588.

29. Benzian H, Monse B, Heinrich-Weltzien R, et al Untreated severe dental decay: a neglected determinant of low Body Mass Index in 12-year-old Filipino children. BMC Public Health. 2011;11:558.

30. Monse B, Duijster D, Sheiham A, Grijalva-Eternod CS, van Palenstein Helderman, W. H, Hobdell $\mathrm{MH}$. The effects of extraction of pulpally involved primary teeth on weight, height and BMI in underweight Filipino children: a cluster randomized clinical trial. BMC Public Health. 2012;12:725.

31. Shim S, Han D, Khang Y. Association between dental caries and delayed growth in Korean children. Caries Res. 2018;52:71-77.

32. Soares ME, Ramos-Jorge ML, de Alencar BM, et al. Influence of masticatory function, dental caries and socioeconomic status on the body mass index of preschool children. Arch Oral Biol. 2017;81:69-73.

33. Kumar S, Tadakamadla J, Johnson NW. Effect of toothbrushing frequency on incidence and increment of dental caries: a systematic review and meta-analysis. J Dent Res. 2016;95:1230-1236.

34. Pries AM, Huffman SL, Adhikary I, et al. High consumption of commercial food products among children less than 24 months of age and product promotion in Kathmandu valley, Nepal. Matern Child Nutr. 2016;12 (suppl 2):22-37.

35. World Health Organization. Guideline: sugars intake for adults and children. Geneva, Switzerland: WHO; 2015. 
Table 1. Grading of severity of untreated dental caries (GUDC)

\begin{tabular}{|c|c|c|c|c|}
\hline \multicolumn{2}{|c|}{ Untreated dental caries $(\mathrm{dt}+\mathrm{DT})$} & \multicolumn{2}{|c|}{$\begin{array}{l}\text { Infection due to untreated dental caries } \\
\text { (pufa+PUFA) }\end{array}$} & \multirow[t]{2}{*}{ Grading $¥$} \\
\hline 0 & None & 0 & No infection & \\
\hline $1-4$ & Moderate & 0 & & Grade 2 \\
\hline$>4$ & Severe & 0 & & \\
\hline $1-4$ & Moderate & $\leq 10 \%$ & Moderate infection & Grade 3 \\
\hline$>4$ & Severe & $\leq 10 \%$ & & \\
\hline $1-4$ & Moderate & $>10 \%$ & Severe infection & Grade 4 \\
\hline$>4$ & Severe & $>10 \%$ & & \\
\hline
\end{tabular}

$¥$ Children with $\mathrm{dt}+\mathrm{DT}$ score $=0$ were considered Grade 1 , whereas those with moderate/severe $\mathrm{dt}+\mathrm{DT}$ score with no pufa+PUFA were considered as Grade 2 . Similarly, those with moderate/severe dt + DT score with $\leq 10 \%$ pufa + PUFA were considered as Grade 3 and finally those with moderate/severe dt+DT score with $>10 \%$ pufa + PUFA were considered as Grade 4. 
Table 2. Proportion (\%) of Thinness, Overweight, and Obesity of Nepalese schoolchildren using the WHO reference, the IOTF reference, and Nepali reference values by age and gender.

\begin{tabular}{|c|c|c|c|c|c|c|c|c|c|c|c|c|}
\hline \multirow{3}{*}{$\begin{array}{c}\text { Age } \\
\text { (Years: } \\
\text { Months) }\end{array}$} & \multirow[t]{3}{*}{ Gender } & \multirow[t]{3}{*}{$\mathrm{n}$} & \multicolumn{4}{|c|}{ IOTF reference ${ }^{a}$} & \multicolumn{3}{|c|}{ WHO reference ${ }^{b}$} & \multicolumn{3}{|c|}{ Nepali reference ${ }^{c}$} \\
\hline & & & \multicolumn{2}{|c|}{ Thinness } & \multirow[t]{2}{*}{ Overweight } & \multirow[t]{2}{*}{ Obesity } & \multirow[t]{2}{*}{ Underweight } & \multirow[t]{2}{*}{ Overweight } & \multirow[t]{2}{*}{ Obesity } & \multirow[t]{2}{*}{ Thinness } & \multirow[t]{2}{*}{ Overweight } & \multirow[t]{2}{*}{ Obesity } \\
\hline & & & $\mathrm{T}-1$ & $\mathrm{~T}-2$ & & & & & & & & \\
\hline \multirow[t]{3}{*}{$5: 0-5: 11$} & Boys & 84 & 39.3 & 8.4 & 7.1 & - & 6.0 & 4.8 & - & 4.8 & 15.5 & 3.6 \\
\hline & Girls & 77 & 31.2 & 10.3 & 3.9 & 2.6 & 5.2 & 3.9 & 2.6 & 5.2 & 6.5 & 2.6 \\
\hline & Total & 161 & 35.4 & 8.1 & 5.6 & 1.2 & 5.6 & 4.3 & 1.2 & 5.0 & 11.2 & 3.1 \\
\hline \multirow[t]{3}{*}{$6: 0-6: 11$} & Boys & 91 & 53.8 & 9.9 & 3.3 & 1.1 & 14.3 & 3.3 & 1.1 & 8.8 & 4.4 & 1.1 \\
\hline & Girls & 86 & 41.9 & 15.1 & 2.3 & 3.5 & 14.0 & 1.2 & 2.3 & 15.1 & 2.3 & 3.5 \\
\hline & Total & 177 & 48.0 & 12.4 & 2.8 & 2.3 & 14.1 & 2.3 & 1.7 & 11.9 & 3.4 & 2.3 \\
\hline \multirow{3}{*}{$\begin{array}{l}12: 0- \\
12: 11\end{array}$} & Boys & 213 & 45.5 & 12.7 & 3.8 & 0.5 & 19.7 & 2.3 & 0.5 & 12.7 & 3.3 & 0.5 \\
\hline & Girls & 201 & 38.3 & 12.4 & 10.9 & 0.5 & 16.4 & 6.5 & 0.5 & 11.9 & 10.4 & 3.0 \\
\hline & Total & 414 & 42.0 & 12.6 & 7.2 & 0.5 & 18.1 & 4.3 & 0.5 & 12.3 & 6.8 & 1.7 \\
\hline \multirow{3}{*}{$\begin{array}{l}15: 0- \\
15: 11\end{array}$} & Boys & 208 & 37.0 & 13.6 & 6.3 & 1.9 & 21.6 & 3.4 & 1.0 & 21.6 & 4.3 & 2.4 \\
\hline & Girls & 175 & 25.1 & 10.9 & 11.4 & 0.6 & 10.9 & 4.0 & - & 10.3 & 7.4 & 0.6 \\
\hline & Total & 383 & 31.6 & 13.1 & 8.6 & 1.3 & 16.7 & 3.7 & 0.5 & 16.4 & 5.7 & 1.6 \\
\hline
\end{tabular}

${ }^{a}$ IOTF BMI cut-offs corresponding to BMI at age 18 , using BMI Thinness Grade- $1(\mathrm{~T}-1)<18.5 \mathrm{~kg} / \mathrm{m}^{2}$, and Thinness Grade-2 $(\mathrm{T}-2)<17 \mathrm{~kg} / \mathrm{m}^{2}$ as Thinness, $>23 \mathrm{~kg} / \mathrm{m}^{2}$ as

Overweight (unofficial Asian cut-offs), and $>27 \mathrm{~kg} / \mathrm{m}^{2}$ as Obesity (unofficial Asian cut-offs) (https://www.worldobesity.org/data/cut,points, used/newchildcutoffs/)

${ }^{\mathrm{b}}$ WHO growth standard tables for ages 5-19-year-olds, using $<-2$ SD as Underweight, $>+1$ SD as Overweight, and $>+2$ SD as Obesity

(http://www.who.int/growthref/who2007_bmi_for_age/en/)

${ }^{\mathrm{c}}$ Nepalese BMI cut-off values ${ }^{15}$, using $<-1.2 \mathrm{SD}$ or $12^{\text {th }}$ percentile as Thinness, $>+1.2 \mathrm{SD}$ or $88^{\text {th }}$ percentile as Overweight, and $>+2.1$ SD or $98^{\text {th }}$ percentile as Obesity 
Table 3. Proportion (\%) of untreated dental caries (dt+DT), infection due to untreated dental caries (pufa+PUFA), and grading of the severity of untreated dental caries (GUDC) stratified by age, gender, location, school type, tooth brushing frequency, dietary habits, body mass index, waist circumference, waist-hip ratio, and waist-to-height ratio.

\begin{tabular}{|c|c|c|c|c|c|c|c|c|c|c|c|c|c|c|}
\hline \multicolumn{2}{|c|}{ Variables } & \multicolumn{4}{|c|}{ Untreated dental caries $(\mathrm{dt}+\mathrm{DT})$} & \multicolumn{4}{|c|}{$\begin{array}{l}\text { Infection due to untreated dental caries } \\
\text { (pufa + PUFA) }\end{array}$} & \multicolumn{5}{|c|}{$\begin{array}{l}\text { Grading of the severity of untreated dental caries } \\
\text { (GUDC) }\end{array}$} \\
\hline & & \multirow{2}{*}{$\begin{array}{c}\text { Healthy } \\
(0)\end{array}$} & \multirow{2}{*}{$\begin{array}{c}\begin{array}{c}\text { Moderate } \\
(1-4)\end{array} \\
32.2\end{array}$} & \multirow{2}{*}{$\begin{array}{c}\text { Severe } \\
(>4)\end{array}$} & $p$-value & 0 & $\leq 10 \%$ & \multirow[t]{2}{*}{$>10 \%$} & $p$-value & $\begin{array}{c}\text { Grade } \\
1\end{array}$ & $\begin{array}{l}\text { Grade } \\
2\end{array}$ & \multirow{2}{*}{$\begin{array}{c}\text { Grade } \\
3 \\
284\end{array}$} & \multirow{2}{*}{$\begin{array}{c}\text { Grade } \\
4 \\
18.6\end{array}$} & $p$-value \\
\hline \multirow[t]{3}{*}{ Age } & 5 -6-year-olds & & & & $<0.001$ & 53.0 & 28.4 & & $<0.001$ & 21.3 & 31.7 & & & $<0.001$ \\
\hline & 12 -year-olds & 33.6 & 55.1 & 11.4 & & 80.4 & 17.1 & 2.4 & & 33.6 & 46.9 & 17.1 & 2.4 & \\
\hline & 15 -year-olds & 37.6 & 49.9 & 12.5 & & 83.3 & 14.4 & 2.3 & & 37.6 & 45.7 & 14.4 & 2.3 & \\
\hline Gender & Boys & 27.5 & 50.0 & 22.5 & 0.011 & 73.3 & 19.6 & 7.0 & 0.970 & 27.5 & 45.8 & 19.6 & 7.0 & 0.017 \\
\hline & Girls & 35.4 & 42.7 & 21.9 & & 73.1 & 19.5 & 7.4 & & 35.4 & 37.7 & 19.5 & 7.4 & \\
\hline Provinces & 1 & 25.8 & 48.5 & 25.8 & 0.001 & 69.6 & 21.1 & 9.3 & 0.002 & 25.8 & 43.8 & 21.1 & 9.3 & $<0.001$ \\
\hline & 2 & 56.6 & 32.5 & 10.8 & & 89.2 & 9.6 & 1.2 & & 56.6 & 32.5 & 9.6 & 1.2 & \\
\hline & 3 & 27.8 & 50.2 & 21.9 & & 76.8 & 21.5 & 1.7 & & 27.8 & 48.9 & 21.5 & 1.7 & \\
\hline & 4 & 26.2 & 48.8 & 25.0 & & 66.7 & 25.0 & 8.3 & & 26.2 & 40.5 & 25.0 & 8.3 & \\
\hline & 5 & 31.3 & 47.0 & 21.7 & & 71.1 & 19.9 & 9.0 & & 31.3 & 39.8 & 19.9 & 9.0 & \\
\hline & 6 & 34.1 & 40.3 & 25.6 & & 71.3 & 17.8 & 10.9 & & 34.1 & 37.2 & 17.8 & 10.9 & \\
\hline & 7 & 30.6 & 48.3 & 21.1 & & 71.9 & 18.6 & 9.5 & & 30.6 & 41.3 & 18.6 & 9.5 & \\
\hline Location & Urban & 31.7 & 47.9 & 20.3 & 0.261 & 74.5 & 19.7 & 5.8 & 0.133 & 31.7 & 42.8 & 19.7 & 5.8 & 0.257 \\
\hline & Rural & 30.8 & 44.9 & 24.3 & & 71.7 & 19.4 & 8.9 & & 30.8 & 40.9 & 19.4 & 8.9 & \\
\hline School types & Public & 32.5 & 48.6 & 18.9 & 0.004 & 75.8 & 17.7 & 6.5 & 0.055 & 32.5 & 43.3 & 17.7 & 6.5 & 0.121 \\
\hline & Private & 29.4 & 43.3 & 27.4 & & 69.3 & 22.4 & 8.3 & & 29.4 & 39.9 & 22.4 & 8.3 & \\
\hline $\begin{array}{l}\text { Frequency of } \\
\text { tooth brushing }\end{array}$ & $\begin{array}{l}\text { Twice or more } \\
\text { daily }\end{array}$ & 35.2 & 50.5 & 14.3 & $<0.001$ & 77.6 & 20.5 & 1.9 & 0.003 & 35.2 & 20.5 & 20.5 & 1.9 & 0.007 \\
\hline & Once daily & 30.5 & 48.9 & 20.6 & & 75.4 & 17.9 & 6.7 & & 30.5 & 17.9 & 17.9 & 6.7 & \\
\hline & $\begin{array}{l}\text { Several times } \\
\text { in a week }\end{array}$ & 28.3 & 38.4 & 33.3 & & 64.0 & 24.6 & 10.9 & & 28.3 & 24.6 & 24.6 & 10.9 & \\
\hline $\begin{array}{l}\text { Sweet bakery } \\
\text { products }\end{array}$ & $\begin{array}{l}\text { Several times } \\
\text { in a month }\end{array}$ & 31.0 & 52.8 & 16.3 & 0.002 & 78.2 & 18.0 & 3.8 & 0.006 & 31.0 & 47.2 & 18.0 & 3.8 & 0.014 \\
\hline & $\begin{array}{l}\text { Several times } \\
\text { in a week }\end{array}$ & 33.0 & 46.2 & 20.8 & & 75.6 & 17.2 & 7.2 & & 33.0 & 42.7 & 17.2 & 7.2 & \\
\hline & $\begin{array}{l}\text { Once or more } \\
\text { Daily }\end{array}$ & 29.9 & 42.2 & 27.9 & & 67.9 & 23.1 & 9.1 & & 29.9 & 38.0 & 23.1 & 9.1 & \\
\hline $\begin{array}{l}\text { Sweets or } \\
\text { candies }\end{array}$ & $\begin{array}{l}\text { Several times } \\
\text { in a month }\end{array}$ & 35.9 & 47.8 & 16.3 & 0.007 & 82.4 & 14.0 & 3.6 & $<0.001$ & 35.9 & 46.6 & 14.0 & 3.6 & 0.001 \\
\hline & $\begin{array}{l}\text { Several times } \\
\text { in a week }\end{array}$ & 29.4 & 50.0 & 20.6 & & 70.3 & 22.4 & 7.3 & & 29.4 & 40.9 & 22.4 & 7.3 & \\
\hline & $\begin{array}{l}\text { Once or more } \\
\text { Daily }\end{array}$ & 27.5 & 46.2 & 26.3 & & 68.9 & 22.7 & 8.4 & & 27.5 & 41.5 & 22.7 & 8.4 & \\
\hline Tea with sugar & $\begin{array}{l}\text { Several times } \\
\text { in a month }\end{array}$ & 37.3 & 44.8 & 17.9 & 0.040 & 80.3 & 16.3 & 3.4 & 0.005 & 37.3 & 42.9 & 16.3 & 3.4 & 0.006 \\
\hline & $\begin{array}{l}\text { Several times } \\
\text { in a week }\end{array}$ & 32.0 & 43.7 & 24.3 & & 79.6 & 16.5 & 3.9 & & 32.0 & 47.6 & 16.5 & 3.9 & \\
\hline & $\begin{array}{l}\text { Once or more } \\
\text { Daily }\end{array}$ & 27.9 & 50.2 & 22.0 & & 70.5 & 21.3 & 8.1 & & 27.9 & 42.7 & 21.3 & 8.1 & \\
\hline IOTF & Thinness & 27.0 & 45.8 & 27.2 & 0.003 & 68.2 & 20.8 & 11.0 & $<0.001$ & 27.0 & 41.2 & 20.8 & 11.0 & $<0.001$ \\
\hline reference & Normal & 35.4 & 46.9 & 17.8 & & 77.8 & 16.9 & 5.3 & & 35.4 & 42.4 & 16.9 & 5.3 & \\
\hline & Overweight & 26.0 & 46.8 & 27.3 & & 66.2 & 32.5 & 1.3 & & 26.0 & 40.3 & 32.5 & 1.3 & \\
\hline & Obese & 15.4 & 53.8 & 30.8 & & 69.2 & 23.1 & 7.7 & & 15.4 & 53.8 & 23.1 & 7.7 & \\
\hline WHO & Underweight & 26.0 & 43.4 & 30.6 & 0.004 & 67.1 & 20.8 & 12.1 & 0.001 & 26.0 & 41.1 & 20.8 & 12.1 & 0.002 \\
\hline reference & Normal & 33.2 & 46.8 & 20.0 & & 75.1 & 18.4 & 6.6 & & 33.2 & 41.9 & 18.4 & 6.6 & \\
\hline & Overweight & 14.0 & 55.8 & 30.2 & & 60.5 & 39.5 & - & & 14.0 & 46.5 & 39.5 & 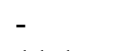 & \\
\hline & Obese & 22.2 & 33.3 & 44.4 & & 66.7 & 22.2 & 11.1 & & 22.2 & 44.4 & 22.2 & 11.1 & \\
\hline Nepalese & Thinness & 25.2 & 43.4 & 31.5 & 0.023 & 69.2 & 20.3 & 10.5 & 0.031 & 25.2 & 44.1 & 20.3 & 10.5 & 0.034 \\
\hline reference & Normal & 33.0 & 47.0 & 20.0 & & 74.8 & 18.2 & 7.0 & & 33.0 & 41.7 & 18.2 & 7.0 & \\
\hline & Overweight & 25.7 & 45.9 & 28.4 & & 62.2 & 33.8 & 4.1 & & 25.7 & 36.5 & 33.8 & 4.1 & \\
\hline & Obese & 18.2 & 50.0 & 31.8 & & 72.7 & 22.7 & 4.5 & & 18.2 & 54.5 & 22.7 & 4.5 & \\
\hline Waist & Normal & 30.9 & 46.7 & 22.3 & 0.737 & 73.8 & 18.7 & 7.5 & 0.069 & 30.9 & 42.8 & 18.7 & 7.5 & 0.062 \\
\hline circumference & Obese & 34.5 & 44.5 & 20.9 & & 68.2 & 27.3 & 4.5 & & 34.5 & 33.6 & 27.3 & 4.5 & \\
\hline Waist-to-Hip & Normal & 32.4 & 46.0 & 21.7 & 0.521 & 74.9 & 19.0 & 6.1 & 0.068 & 32.4 & 42.5 & 19.0 & 6.1 & 0.137 \\
\hline Ratio & Obese & 29.1 & 47.6 & 23.3 & & 69.8 & 20.6 & 9.5 & & 29.1 & 40.7 & 20.6 & 9.5 & \\
\hline Waist-to- & Normal & 31.7 & 46.6 & 21.7 & 0.388 & 73.8 & 19.1 & 7.1 & 0.325 & 31.7 & 42.4 & 19.1 & 7.1 & 0.498 \\
\hline height ratio & Obese & 27.2 & 45.6 & 27.2 & & 67.0 & 24.3 & 8.7 & & 27.2 & 39.8 & 24.3 & 8.7 & \\
\hline
\end{tabular}


Table 4. Generalized linear model with negative binomial distribution of the untreated dental caries (dt+DT) and infection due to untreated dental caries (pufa+PUFA) as dependent variables and socio-demography (age, gender, location, school types), frequency of tooth brushing, dietary habits, and BMI (the IOTF, WHO, and Nepalese growth references) as covariates.

\begin{tabular}{|c|c|c|c|c|c|c|c|}
\hline \multicolumn{2}{|c|}{ Explanatory factors } & \multicolumn{3}{|c|}{$\begin{array}{c}\text { Untreated dental caries }(\mathrm{dt}+\mathrm{DT}) \\
\mathrm{RR}(95 \% \mathrm{CI})\end{array}$} & \multicolumn{3}{|c|}{$\begin{array}{l}\text { Infection due to untreated dental caries (pufa + PUFA) } \\
\qquad R R(95 \% \mathrm{CI})\end{array}$} \\
\hline & & IOTF reference & WHO reference & Nepalese reference & IOTF reference & WHO reference & Nepalese reference \\
\hline \multirow[t]{3}{*}{ Age } & 5-6-year-olds & $2.68(2.23-3.22)^{* *}$ & $2.70(2.25-3.25)^{* *}$ & $2.70(2.25-3.24)^{* *}$ & $2.27(1.67-3.06)^{* *}$ & $2.28(1.68-3.10)^{* *}$ & $2.31(1.70-3.12)^{* *}$ \\
\hline & 12-year-olds & $1.01(0.86-1.19)$ & $1.01(0.86-1.18)$ & $1.02(0.86-1.19)$ & $1.04(0.80-1.35)$ & $1.05(0.80-1.37)$ & $1.05(0.80-1.37)$ \\
\hline & 15-year-olds & 1.00 & 1.00 & 1.00 & 1.00 & 1.00 & 1.00 \\
\hline \multirow[t]{2}{*}{ Gender } & Boys & $1.21(1.05-1.39)^{* *}$ & $1.22(1.06-1.40)^{* *}$ & $1.22(1.06-1.40)^{* *}$ & $1.04(0.83-1.31)$ & $1.05(0.83-1.32)$ & $1.07(0.85-1.34)$ \\
\hline & Girls & 1.00 & 1.00 & 1.00 & 1.00 & 1.00 & 1.00 \\
\hline \multirow[t]{2}{*}{ Location } & Urban & $0.99(0.86-1.14)$ & $0.99(0.86-1.14)$ & $0.99(0.86-1.14)$ & $0.91(0.72-1.15)$ & $0.91(0.72-1.14)$ & $0.91(0.72-1.14)$ \\
\hline & Rural & 1.00 & 1.00 & 1.00 & 1.00 & 1.00 & 1.00 \\
\hline \multirow{2}{*}{$\begin{array}{l}\text { School } \\
\text { Types }\end{array}$} & Private & $1.07(0.93-1.24)$ & $1.07(0.93-1.24)$ & $1.07(0.93-1.23)$ & $1.03(0.81-1.31)$ & $1.03(0.81-1.31)$ & $1.02(0.80-1.29)$ \\
\hline & Public & 1.00 & 1.00 & 1.00 & 1.00 & 1.00 & 1.00 \\
\hline \multirow{3}{*}{$\begin{array}{l}\text { Frequency } \\
\text { of tooth } \\
\text { brushing }\end{array}$} & Once daily & $1.04(0.81-1.33)$ & $1.05(0.80-1.32)$ & $1.03(0.81-1.33)$ & $1.16(0.76-1.74)$ & $1.15(0.76-1.45)$ & $1.15(0.76-1.75)$ \\
\hline & Several times in a week & $1.06(0.88-1.27)$ & $1.06(0.88-1.27)$ & $1.06(0.89-1.27)$ & $1.21(0.89-1.62)$ & $1.21(0.89-1.64)$ & $1.20(0.89-1.63)$ \\
\hline & Twice or more daily & 1.00 & 1.00 & 1.00 & 1.00 & 1.00 & 1.00 \\
\hline \multirow{3}{*}{$\begin{array}{l}\text { Sweet } \\
\text { Bakery } \\
\text { Products }\end{array}$} & Once or more daily & $0.97(0.81-1.15)$ & $0.96(0.81-1.14)$ & $0.96(0.81-1.15)$ & $0.98(0.73-1.30)$ & $0.98(0.73-1.30)$ & $0.98(0.73-1.30)$ \\
\hline & Several times in a week & $0.99(0.84-1.18)$ & $0.99(0.83-1.18)$ & $0.99(0.83-1.18)$ & $1.02(0.76-1.34)$ & $1.02(0.77-1.35)$ & $1.02(0.76-1.35)$ \\
\hline & $\begin{array}{l}\text { Several times in a } \\
\text { month }\end{array}$ & 1.00 & 1.00 & 1.00 & 1.00 & 1.00 & 1.00 \\
\hline \multirow{3}{*}{$\begin{array}{l}\text { Sweets or } \\
\text { Candies }\end{array}$} & Once or more daily & $1.29(1.09-1.52)^{*}$ & $1.30(1.10-1.53)^{*}$ & $1.30(1.10-1.53)^{*}$ & $1.27(0.96-1.68)$ & $1.27(0.96-1.68)$ & $1.30(0.98-1.71)$ \\
\hline & Several times in a week & $1.14(0.96-1.58)$ & $1.15(0.97-1.37)$ & $1.15(0.97-1.36)$ & $1.27(0.96-1.69)$ & $1.27(0.96-1.69)$ & $1.29(0.97-1.72)$ \\
\hline & $\begin{array}{l}\text { Several times in a } \\
\text { month }\end{array}$ & 1.00 & 1.00 & 1.00 & 1.00 & 1.00 & 1.00 \\
\hline \multirow{3}{*}{$\begin{array}{l}\text { Tea with } \\
\text { Sugar }\end{array}$} & Once or more daily & $1.19(1.01-1.38)^{*}$ & $1.17(0.99-1.37)$ & $1.18(1.01-1.38)^{*}$ & $1.22(0.95-1.58)$ & $1.24(0.96-1.61)$ & $1.22(0.95-1.59)$ \\
\hline & Several times in a week & $1.23(0.96-1.67)$ & $1.22(0.95-1.56)$ & $1.23(0.96-1.59)$ & $0.99(0.65-1.50)$ & $1.00(0.65-1.53)$ & $0.99(0.65-1.52)$ \\
\hline & $\begin{array}{l}\text { Several times in a } \\
\text { month }\end{array}$ & 1.00 & 1.00 & 1.00 & 1.00 & 1.00 & 1.00 \\
\hline \multirow[t]{3}{*}{ BMI } & Low & $1.11(0.96-1.28)$ & $1.07(0.89-1.30)$ & $1.11(0.90-1.36)$ & $1.15(0.91-1.47)$ & $1.13(0.83-1.55)$ & $1.09(0.78-1.53)$ \\
\hline & High & $1.18(0.92-1.52)$ & $1.30(0.96-1.77)$ & $1.20(0.96-1.52)$ & $0.96(0.63-1.48)$ & $0.86(0.50-1.47)$ & $1.07(0.71-1.59)$ \\
\hline & Normal & 1.00 & 1.00 & 1.00 & 1.00 & 1.00 & 1.00 \\
\hline
\end{tabular}

${ }^{* *}$-value $<0.001-{ }^{*} p$-value $\leq 0.05$

RR (95\% CI): Rate Ratio (95\% confidence interval) 
Fig 1. Mixed effects multinomial logistic regression models for the association between the grading of the severity of untreated dental caries (GUDC) and BMI (IOTF- WHO- and Nepalese growth references). The odds ratio (95\% confidence interval) for (A) grade 1 vs grade 2, (B) grade 1 vs grade 3 , and (C) grade 1 vs grade 4 in children with low and high BMI using normal BMI group as reference. In each model, age, gender, location, school types, frequency of tooth brushing, and dietary habits were adjusted.

A

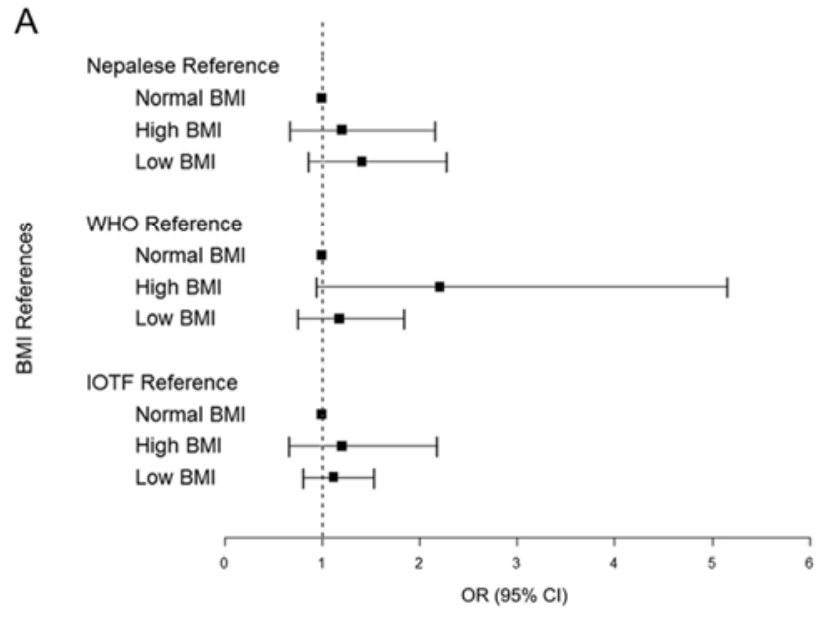

C

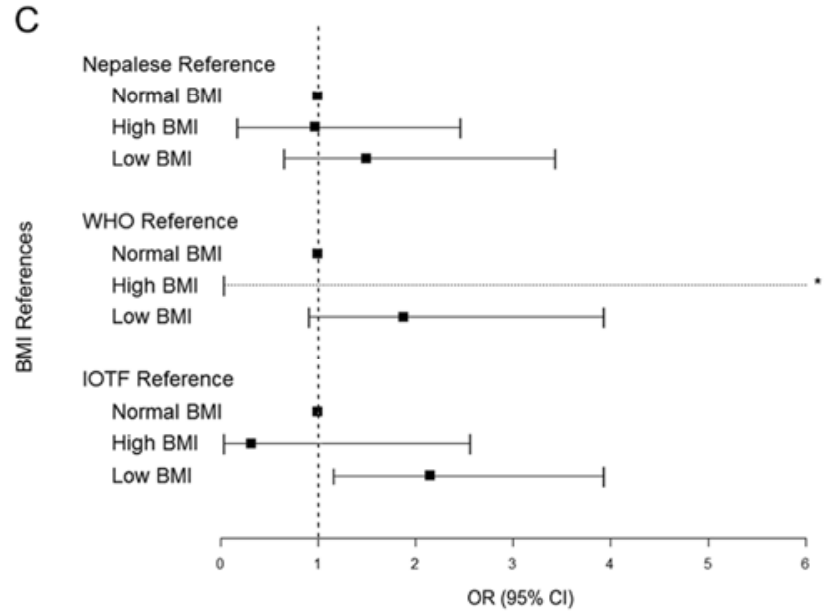

B

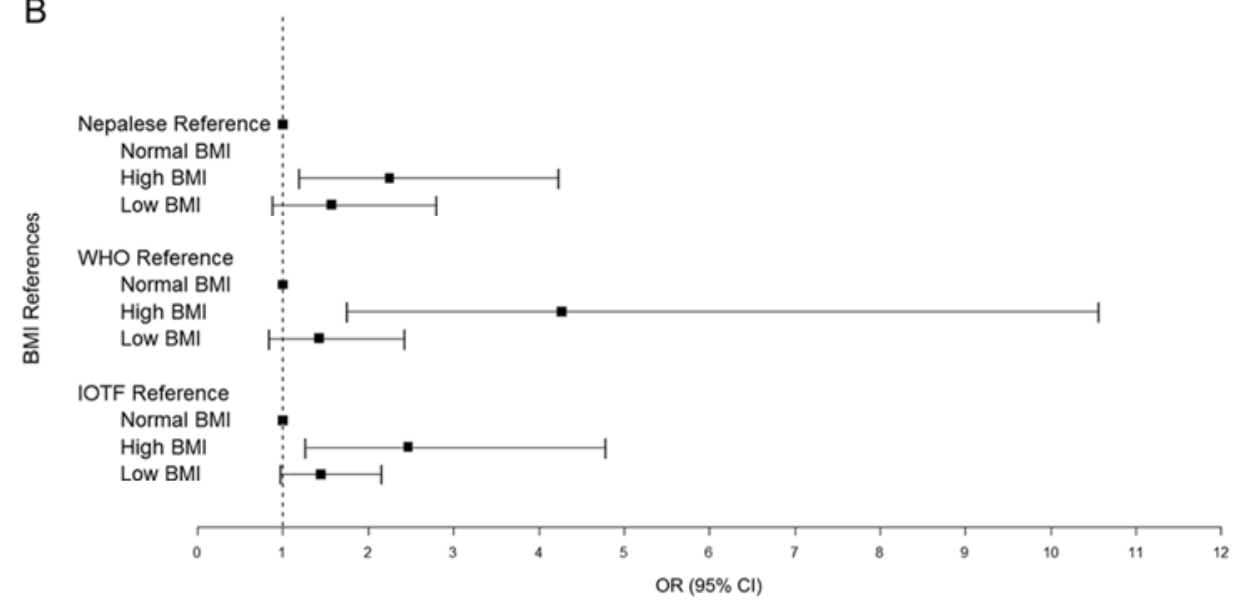

